\title{
Oral Health Status of Rural-Urban Migrant Children in South China
}

\section{Xiao-Li Gao}

BDS, Msc, PhD

Post-doctoral Fellow, Dental Public Health, Faculty of Dentistry, University of Hong Kong

\section{Colman McGrath}

BA, BDentSc, FDSRCS, DDPHRCS, MSc, FFDRCS, PhD

Professor, Dental Public Health, Faculty of Dentistry, University of Hong Kong

Huan-Cai Lin

BDS, Msc, PhD

Professor, Preventive Dentistry, Guanghua School of Stomatology, Sun Yat-sen University, China

\author{
Correspondences to be sent to: \\ Dr. Xiao-Li Gao \\ Dental Public Health \\ Faculty of Dentistry \\ The University of Hong Kong \\ Prince Philip Dental Hospital \\ 34 Hospital Road, Sai Ying Pun, Hong Kong \\ Tel: (852) 28590481 \\ Fax: (852) 28587874 \\ Email: gaoxl@hkucc.hku.hk
}

Number of words in the summary: 200

Number of words in the text: 3483 (Summary to Acknowledgement)

Number of tables: 6

Number of cited references: 18 


\section{Oral Health Status of \\ Rural-Urban Migrant Children in South China}

\section{SUMMARY}

Background: In China there is a massive rural-urban migration and the children of migrants are often unregistered residents (a 'floating population'). Aim: This pilot study aimed to profile the oral health of migrant children in South China's principal city of migration and identify its sociodemographic/behavioral determinants. Design: An epidemiological survey was conducted in an area of Guangzhou among 5-year-old migrant children $(\mathrm{n}=138)$ who received oral examinations according to the World Health Organization criteria. Parents' oral health knowledge/attitude, child practices and impact of children's oral health on their quality of life (QoL) were assessed. Results: The caries rate and mean (SD) dmft were 86\% and 5.17 (4.16), respectively, higher than those national statistics for both rural and urban areas $(\mathrm{p}<0.05)$. Oral hygiene was satisfactory (DI-S $<1.0$ ) in 3\% of children. Oral health impacts on QoL were considerable; $60 \%$ reported one or more impacts. 58\% variance in "dmft" was explained by "non-local-born", "low-educated parents”, "bedtime feeding”, "parental unawareness of fluoride’s effect and importance of teeth”, and "poor oral hygiene" (all p<0.05). "Non-local-born" and "dmft" indicated poor oral healthrelated QoL (both $\mathrm{p}<0.05$ ), accounting for $32 \%$ of variance. Conclusion: Oral health is poor among rural-urban migrant children and requires effective interventions in targeted sub-groups. 


\section{Introduction}

Massive internal migration has been an emerging pattern of population distribution in many countries, with approximately 740 million internal migrants worldwide ${ }^{1}$. In China, economic reforms and rapid urbanization have led to large migration from the countryside to cities (rural-urban migration) ${ }^{2}$. China’s rural-urban migrant population has expanded from 30 million in the 1980s to about 180 million in 2000s, exceeding 10 percent of the national population ${ }^{3}$. It was expected that, by 2025, Chinese cities will face an influx of another 200 million migrants, with half the population in the medium and large cities being migrants ${ }^{4}$.

The rural-urban migrants in China are often called the "floating population", a name vividly depicting their living status, high mobility and lack of official registration documentation. The rural-urban migration poses significant challenges, especially for China's welfare system concerning both local and migrant residents ${ }^{5}$. Recently, the National People's Congress of China has highlighted the plight of the “floating population’ and outlined policies for education and basic health services ${ }^{6}$.

Despite the regular surveillance of oral health in China and the enormous sampling efforts, rural-urban migrants were excluded or underrepresented in national surveys owing to their nonresident status ${ }^{7}$. There is an urgent need to understand the oral health concerns of the rural-urban migrant children in China as the government attempts to address health disparities between ruralurban migrants and the rest of the population.

As the frontier of economic development, Guangzhou, the metropolitan in South China and the capital city of Guangdong Province, is hosting more than 3,200,000 migrants from rural areas, comprising over $30 \%$ of the population of the city; About 200,000 children have migrated to Guangzhou with their parents ${ }^{8}$. Using the migrant children in Guangzhou as a model, this pilot 
study aimed to profile the oral health status of migrant children in China and to identify the sociodemographic and behavioral determinants of their oral health.

\section{Methods}

\section{Study sample}

Due to the high mobility of the migrant families and the incomplete registration of their residence, ideal sampling frame for conducting surveys among them is not available. Nevertheless, most children are attending non-public schools in areas where migrant communities typically reside. These non-public schools thus create a practical and optimal channel to access the migrant children.

After obtaining ethical approval from the Institutional Review Board of the University of Hong Kong and parental informed consent, children aged 5 years were recruited from the preschool classes in a migrant children's school in Haizhu District, one of Guangzhou's administrative districts where a large number of migrant families reside in. This school is one of the 24 schools run by the largest education body providing education to migrant children in Guangzhou.

\section{Oral examination}

The tooth status and oral hygiene of children were evaluated by a trained examiner. For monitoring the intra-examiner reliability, duplicate examinations were carried out on 10\% randomly selected participants. 
The oral hygiene status was assessed using the Simplified Debris Index (DI-S), which is the debris component of the Simplified Oral Hygiene Index (OHI-S) ${ }^{9}$. The DI-S values, with a possible range of $0-3$, were further categorized for representing five levels of mouth cleanliness: very good (0-0.5), good (0.6-1.0), moderate (1.1-1.5), poor (1.6-2.0), and very poor (2.1-3.0) ${ }^{10}$.

Dental caries were registered at the cavitation level according to the World Health Organization method and criteria ${ }^{11}$. The tooth status was mainly assessed by visual inspection, aided by tactile inspection if necessary. Although the teeth were neither cleaned nor dried before the assessment, the debris obscuring the visual inspection was removed. No radiographs were taken.

\section{Questionnaire survey}

A self-administered questionnaire was completed by parents. The participating school has facilitated the distribution and collection of questionnaires. The questionnaire used in this study represents a combination of selected questions from the $3^{\text {rd }}$ National Oral Health Survey in China $^{7}$ and the Chinese version of the Early Childhood Oral Health Impact Scale (ECOHIS) ${ }^{12}$. The questionnaire was structured to collect information on: (a) demographic background (age, gender, place of birth, and place of household registration); (b) socio-economic status (family

income and parents' education attainment and occupation); (c) residence history of children and parents; (d) children's oral health behaviors (feeding history, diet, oral hygiene practice, and utilization of dental care services); (e) parental knowledge and attitude on oral health; and (f) impact of oral health on children's quality of life (QoL) measured by ECOHIS.

ECOHIS relies on parental ratings of 13 items grouped into two scales, namely, Child Impact Section (CIS) and Family Impact Section (FIS). The CIS has four sub-domains: child 
symptom, child function, child psychology, and child self-image and social interaction. The FIS has two domains: parental distress and family function. The response for each question is rated on a 5-point Likert scale to record how often an event has occurred during the life of the child: $0=$ never; 1 = hardly ever; 2 = occasionally; 3 = often; 4 = very often. A "don't know" option was also included. Summary ECOHIS scores were derived by summating responses to all 13 items (total scores can range from 0 to 52). CIS and FIS scores can range from 0 to 36 and 0 to 16 , respectively. A high ECOHIS score indicates greater oral health impact (more oral health problems) and poorer oral health-related QoL.

\section{Reports to parents}

After the survey, a report was sent to the parents of each child, explaining the child's oral health status and need for dental treatments, if any.

\section{Data analysis}

Caries prevalence (\% affected, \% with rampant caries, dmft, dmfs), oral health behaviors and oral health-related QoL were derived from descriptive statistics. Intra-examiner reliability was evaluated by the Cohen's Kappa statistics and the Intra-class Correlation Coefficient, for dental caries examination and oral hygiene evaluation, respectively. Comparisons were made between the oral health parameters of migrant children and national statistics for both rural and urban areas at a significance level of 0.05. Chi-square tests were used for the comparison of proportions. Tukey pos-hoc tests or independent t-tests (as appropriate) were used to compare means, since the normal distribution and homogeneity of variance were supported by normality test and Levene tests. 
Multiple linear regressions were applied to identify the socio-demographic and behavioral determinants of dental caries in these migrant children, while oral health-related QoL was analyzed likewise with regard to its relationship with socio-demographic factors and dmft. The dependent variables were dmft score for the former analysis and ECOHIS score for the latter analysis. If a variable reached $(\mathrm{p}<0.05)$ or approached $(0.05 \leqq \mathrm{p}<0.1)$ a significant correlation with the dependent variable in the bivariate analysis, it was entered as an independent variable in the multiple regressions.

\section{Results}

Among all 161 children enrolled in the preschool classes, 138 participated in this study. The response rate was $85.7 \%$. The socio-demographic characteristics of the study sample are presented in Table 1.

The intra-examiner reliability for caries examination was high (Kappa=0.945). The dental caries prevalence and severity in this group of children were summarized in Table 2. An overwhelming majority (85.5\%) of children were affected by caries $(\mathrm{dmft}>0)$. More than half (51.9\%) children were found with rampant caries, defined as caries affecting the smooth surfaces of two or more maxillary incisors ${ }^{13}$. The mean (SD) dmft and dmfs were 5.17 (4.16) and 7.93 (8.36), respectively. Almost all (99.4\%) affected teeth were untreated decayed teeth. The caries prevalence and severity of non-local-born migrant children was significantly higher than that of the local-born (all $\mathrm{p}<0.05)$. Comparisons with the data collected through the latest $\left(3^{\text {rd }}\right)$ National Survey of Oral Health ${ }^{7}$ showed that the caries rate and dmft in non-local-born migrant children were significantly higher than those national statistics for both rural and urban areas (all $\mathrm{p}<0.05$ ). 
No significant difference was found between the caries experience of local-born migrant children and the national statistics $(\mathrm{p}>0.05)$.

The intra-examiner reliability for oral hygiene evaluation was high (Intra-class Correlation Coefficient=0.902). Only 2.9\% of children had "very good" (DI-S 0-0.5) or "good" (DI-S 0.6-1.0) oral hygiene. The oral hygiene was "moderate" (DI-S 1.1-1.5) in 37.7\% of children, "poor" (DI-S 1.6-2.0) in 31.9\% and "very poor" (DI-S 2.1-3.0) in 27.5\% of the participants. The mean (SD) DI-S was 1.81 (0.49).

Table 3 describes children's oral health practice and parental knowledge and attitudes on oral health. In general, oral health knowledge and attitudes among parents were acceptable. The majority of parents were aware of the roles of "sugar/sweets" (71.5\%) and "insufficient toothbrushing” (53.8\%) in causing dental caries, with $16.2 \%$ of parents attributing caries to bacteria. Meanwhile, approximately a third of parents (34.6\%) held the traditional belief of "tooth worm" as the pathogen of caries and 11.5\% parents regarded caries as a result of "excess heat” (an Asian belief emphasizing a particular imbalance in the body). The fatalistic oral health belief (i.e. "having good or bad teeth is predetermined and has nothing to do with how one protects his/her teeth") was held by a minority (10\%) of parents. The main sources of oral health knowledge were mass media, including TV/radio (for 62\% of parents) and newspaper/magazine (for $36 \%$ of parents). Only $6.2 \%$ migrant parents received oral health information from their family members, relatives, or friends. This percentage was significantly lower than the national statistics in both urban (26\%) and rural areas $(17 \%)^{7}$. Compared with rural residents in China, more migrant parents received oral health information through community programs (8.5\% vs. 2\%). The percentage of migrant parents receiving oral health message from children's kindergartens/schools was $8.5 \%$, similar to that in rural areas (9\%) and significantly lower than 
that for the urban citizens (15\%). Children's oral health behaviors (reported by parents) were generally unfavorable: $89.2 \%$ of children had never visited a dentist; $35.1 \%$ of children took sweets frequently at bedtime; more than a quarter (26.7\%) had not started brushing teeth at the time of survey (i.e. age of 5); only $11.5 \%$ of children brushed their teeth twice a day.

The impacts of children's oral health on their QoL were considerable, with $60.2 \%$ reported one or more impacts (Table 4). The mean (SD) of the total ECOHIS score was 10.33 (8.91), with a median (Inter-Quartile Range) as 11.0 (18.0). The oral health impact was high in the sub-domains of “child symptoms” (51.5\% with one or more impacts) and “child function” (46.2\% with one or more impacts), substantial on "child psychology" (32.6\% with one or more impacts) and "parental distress" (37.2\% with one or more impacts), and low on "self-image and social interaction" (11.6\% with one or more impacts) and "family function” (17.1\% with one or more impacts).

Multiple regressions identified several socio-demographic and behavioral variables as determinants of dental caries (Table 5) and oral health impact on children's quality of life (QoL) (Table 6). "Being non-local-born” increased the number of carious teeth by 2.61. "Low-educated parents” indicated high caries rate. Bedtime feeding at 12 months of age was associated with a 2.83 increase in “dmft”. Number of carious teeth was also associated with "bedtime sweets” and "parental unawareness of the caries-preventive effect of fluoride and the importance of teeth erupting after 6 years of age”. "Poor oral hygiene” indicated high caries rate, with one unit increase in DI-S linked to a 2.51 increase in number of carious teeth. All these factors explained $58 \%$ of variance in $\mathrm{dmft}$.

“Being non-local-born” and “dmft” indicated poor oral health-related QoL (both p<0.05). Increase of one carious tooth led to a 0.95 increase in ECOHIS score. "Being non-local born" 
was linked to a 4.06 increase in ECOHIS score. These two variables explained 32\% of variance in oral health-related QoL.

\section{Discussion}

The health of migrants is currently a spotlighted issue worldwide. In the Global Consultation on Migrant Health hosted by the World Health Organization in 2010, consensuses have been reached that migrants' health is a central element for social cohesion for contemporary societies and a priority area for reducing health disparity ${ }^{1}$. Addressing the large number of ruralurban migrants in China and their health care needs, this pilot study represents the first attempt for understanding the oral health of migrant children in this great nation.

A convenience sample selected from a migrant children's school was adopted in this study owing to the lack of a comprehensive sampling frame of migrant children who are often officially 'unregistered'. Despite the limitation in sampling, based on our communication with the local authorities and education bodies, it was believed that the participating school is a 'typical' migrant school in terms of geographic location, type of school operation, tuition fee, and students' demographic and socioeconomic profiles. Although preschool education is not compulsory in China, most children in cities attend preschool education programs at least at the age of 5. In Guangzhou, a survey in 2002 showed that $60 \%$ migrant children received preschool education ${ }^{14}$. It should be borne in mind that access to pre-school education may be relatad to family socio-economic circumstances and thus the oral health status of the migrants may in fact be even poorer than that of this study population. 
Our results have revealed that the caries prevalence in non-local-born migrant children is significantly higher than the national statistics of both rural and urban areas. The poorer oral health of these children as compared with their urban counterpart is not surprising, since caries prevalence in China's rural areas, where the migrants originated from, is higher than that of urban residents ${ }^{7}$. The finding that the caries rate in non-local-born migrant children is even higher than the statistics in rural population suggests a possible deterioration of migrant children's oral health after their arrival in the host city. Such deterioration might have partly stemmed from dietary changes of migrants. After settling down in cities, the migrants have to adopt a diet with more refined foods, which, compared with the rural-style natural foods, are likely to be more cariogenic. Although healthy food and snacks are available in cities and are often the choices of local residents, these healthier choices are often not the affordable option for migrant families. Meanwhile, sugary snacks are readily accessible in cities and might be taken as a psychological comfort by migrant children who are facing various stresses (loneliness etc) in the host cities. Besides the frequent sweet intakes, other common unfavorable oral health behaviors in this group of migrant children are the late start and insufficient frequency of toothbrushing, poor oral hygiene, and low utilization of dental care services, which, in aggregation, exacerbated the oral health problems in this population.

In contrast to the poor oral health behaviors of migrant children, the oral health knowledge and attitude of their parents are reasonably satisfactory and comparable to the findings in the national population ${ }^{7}$. This may be due to the easy access to oral health information disseminated through mass media and from other sources in cities. The obvious gap between parental knowledge/attitude and children's practice on oral health might be attributable to the migrant families' financial constraints and their various life challenges, under which oral 
health may receive low priority ${ }^{15}$.

Although a poorer oral health was found in non-local-born children as compared with those local-born, no association was found between "duration of residence” and their oral health. This implies that the better oral health of local-born children is not due to a longer residence of their family in the city. Behind the decision of delivering a child in the host city might be many other factors such as a better-off or more stable financial condition, better integration of the parents into the local society, and a higher perception and priority to child's health. Interestingly, in this group of preschool children aged 5 years, a lower caries severity was found among those whose parents were aware of the importance of protecting teeth erupting after 6. Presumably, with such a perception, parents may pay more attention to cultivating children's oral health habits from a young age.

In this study, efforts have been made to understand migrant children's dietary habits and oral hygiene practice. Nevertheless, no attempts were made to collect information on their fluoride exposures. In China, water fluoridation is not implemented in any city/area. Prescriptions of systemic and topical fluorides are very rare, particularly for young children. Fluoride-containing toothpastes are therefore the only common non-natural source of fluorides. According to our experience of oral health survey in China, parents, particularly those lesseducated such as migrant workers, are often unsure about whether their children's toothpastes contain fluorides. Therefore, questions on fluoridated toothpastes were not included in this study. However, since fluoride-containing toothpastes dominate the market in China's cities ${ }^{16}$, it can be expected that most migrant children who have established toothbrushing habit are exposed to toothpaste fluorides. This again highlighted the importance of promoting toothbrushing in this population. 
Our results have shown that only $6.2 \%$ migrant parents received oral health information from their family members, relatives, or friends, while $26 \%$ and $17 \%$ Chinese residents in urban and rural areas, respectively, did so ${ }^{7}$. This manifests the loss in social networks and family supports when migrants left their homestead for an unfamiliar city. Though migrant parents are more exposed to community programs for oral health compared with their rural counterpart (8.5\% vs. $2 \%)$, the opportunity that they receive oral health message from children's kindergartens/schools (8.5\%) remains similar to that in rural areas (9\%) and is significantly lower than that for the urban citizens (15\%), probably due to the limited resources in migrant children's schools and the lack of financial and professional supports that these schools receive from the government. These findings point to an urgent need of reinforcing community programs and establishing school-based outreaches for migrant population. While the oral health information acquired through mass media tends to be overly generic, community/school programs with the professional supports of paediatric dentists and public health workers could provide specifically tailored interventions for migrant families and motivate them more effectively in protecting their oral health. In the clinical setting, migrant-sensitive dental practice should be advocated to improve the quality of dental management and enhance paediatric dentists' communication with migrant children and their parents ${ }^{1,17}$.

Findings from this study also highlight the impacts of children's oral health on their quality of life with most parents perceiving child and family impacts. Most frequently impacts were related to symptoms and physical function. Comparable data on oral health-related quality of life in Asia among young children is scant but the literature indicates a greater extent of social impact among Chinese preschoolers in neighboring Hong Kong ${ }^{12}$. This may reflect both the absolute and relative economic differences between the communities. Findings from our study 
have identified dental caries experience and place of birth as key predictors of oral health-related quality of life. This again indicates the rural-urban migrants' plight, which shall be considered in line with recent governments initiatives to improve life quality for all in China ${ }^{18}$.

\section{What this paper adds}

- This pilot study, using migrant children in Guangzhou as a model, revealed a poor oral health in the migrant population related to a number of social and behavioral attributes.

- This report suggests the need to incorporate oral health initiatives in China's central government policies and programmes for improving migrants' health.

- The findings of this paper are also likely to have implications for all regions and countries experiencing mass rural-urban migration.

\section{Why this paper is important to paediatric dentists}

- This paper helps to arouse paediatric dentists' attention to the significance of migrantsensitive dental practice.

- The socio-demographic and behavioral determinants of migrants' oral health serve as references for paediatric dentists to tailor health education and preventive measures for migrant children.

- This report encourages paediatric dentists to contribute their expertise to improving migrants' oral health. 


\section{Acknowledgement}

We appreciate the support of the participating migrant school and the assistance of the school teachers and other staff members.

\section{References}

1 World Health Organization. Challenges facing health of migrants to be tackled at key meeting. Marid, March 2010. http://www.who.int/hac/events/3march2010/en/index.html. Accessed on March 23, 2010.

2 Hu X, Cook S, Salazar MA. Internal migration and health in China. Lancet. 2008; 372 (9651):1717-9.

3 China Government Affair Net. Rural-urban migrants exceed 0.18 billion in 2005. http://www.ccgov.net.cn/. 2006.

4 McKinsey Global Institute. Preparing for China's urban billion. http://www.mckinsey.com/MGI/. 2008.

5 Seibert A. From somewhere to nowhere. China's internal migrants. Lars Müller Publishers. ISBN 978-3-03778-146-3. 2008.

6 National People's Congress. Report on the Work of the Government. Third Session of the Eleventh National People's Congress. March 2010.

$7 \quad$ PRC National Committee for Oral Health. Report of the third national survey of oral health. Ed. Xiaoquan Qi. People’s Medical Publishing House. June 2008. ISBN 978-7-117-10149-3.

8 Guangzhou Bureau of Statistics. opulation census 2003. http://www.gzstats.gov.cn. 2003.

9 Greene JC, Vermillion JR. The simplified oral hygiene index. J Am Dent Assoc. 1964; 68:7-13.

10 Villalobos-Rodelo JJ, Medina-Solís CE, Maupomé G et al. Socioeconomic and Sociodemographic Variables Associated With Oral Hygiene Status in Mexican Schoolchildren Aged 6 to 12 Years. J Periodontol. 2007; 78(5): 816-22.

11 World Health Organization (WHO). Oral health surveys - Basic methods. 4th version. Geneva 1997.

12 Lee GH, McGrath C, Yiu CK et al. Translation and validation of a Chinese language version of the Early Childhood Oral Health Impact Scale (ECOHIS). Int J Paediatr Dent. 2009; 19(6): 399-405.

13 Al-Malik MI, Holt RD, Bedi R. Erosion, caries and rampant caries in preschool children in Jeddah, Saudi Arabia. Community Dent Oral Epidemiol. 2002; 30(1):16-23.

14 Shen X. Education of migrant workers' children in Guangzhou - sociological perspectives. Youth Studies. 2004; 11.

15 Wong FKD. Rural migrant works in urban China: living a marginalized life. Int J Soc Welf. 2008; 16 (1): 32-40.

16 Chinese Chemical Industry Society. Market report: fluoride-containing toothpastes. http://www.chemhoo.com/Report/3/20090628171578.html. 2009.

17 American Academy of Pediatrics. Health care for children of migrant families. Pediatrics. 1989; 84(4), 739-740. 
18 Guangdong People's Congress. Regulations on the service and management of the mobile population in Guangdong province (revision). The Guangdhong People's Congress. www.rd.gd.cn. 2009. 
Table 1. Socio-demographic characteristics of the study sample

\begin{tabular}{|c|c|c|}
\hline & $\mathbf{n}$ & $\%$ \\
\hline \multicolumn{3}{|l|}{ Gender (child) } \\
\hline Male & 81 & 58.7 \\
\hline Female & 57 & 41.3 \\
\hline \multicolumn{3}{|l|}{ Place of birth (child) } \\
\hline Local born & 47 & 34.1 \\
\hline Non-local born & 91 & 65.9 \\
\hline \multicolumn{3}{|l|}{ Father's education } \\
\hline No education/primary & 28 & 21.4 \\
\hline Low secondary & 70 & 53.4 \\
\hline High secondary and above & 33 & 25.2 \\
\hline \multicolumn{3}{|l|}{ Mother's education } \\
\hline No education/primary & 37 & 28.2 \\
\hline Low secondary & 66 & 50.4 \\
\hline High secondary and above & 28 & 21.4 \\
\hline \multicolumn{3}{|l|}{ Father' occupation } \\
\hline Unemployed & 9 & 6.9 \\
\hline Laborer/manual worker & 83 & 63.4 \\
\hline Management/business/self-employed & 39 & 29.8 \\
\hline \multicolumn{3}{|l|}{ Mother's occupation } \\
\hline Unemployed & 35 & 26.7 \\
\hline Laborer/manual worker & 78 & 59.5 \\
\hline Management/business/self-employed & 18 & 13.7 \\
\hline \multicolumn{3}{|l|}{ Family income (CNY / person-month) * } \\
\hline $0-500$ & 43 & 33.6 \\
\hline $501-1000$ & 65 & 50.8 \\
\hline $1001-2000$ & 15 & 11.7 \\
\hline$>2000$ & 5 & 3.9 \\
\hline Range & \multicolumn{2}{|c|}{$90-5000$} \\
\hline Mean (SD)** & \multicolumn{2}{|c|}{$824(615)$} \\
\hline Median (IQR)*** & \multicolumn{2}{|c|}{$667(500)$} \\
\hline Total & 138 & 100 \\
\hline
\end{tabular}

\footnotetext{
* The average income (824 CNY/person-month) of these migrant families was only $39 \%$ of the average income of all Guangzhou residents (2110 CNY/person-month) (data from Guangzhou Bureau of Statistics; Guangzhou statistical yearbook 2008. Economy and Income http://www.gzstats.gov.cn/)

** SD: standard deviation; *** IQR: inter-quartile range.
} 
Table 2. Caries prevalence and severity of the study sample and the national population

\begin{tabular}{cccccc}
\hline & $\begin{array}{c}\text { Age } \\
\text { (yrs) }\end{array}$ & $\begin{array}{c}\text { \% affected } \\
\text { (dmft }>\mathbf{0})\end{array}$ & $\begin{array}{c}\text { \% with } \\
\text { rampant caries ** }\end{array}$ & $\begin{array}{c}\text { Mean (SD) } \\
\text { dmft *** }\end{array}$ & $\begin{array}{c}\text { Mean (SD) } \\
\text { dmfs *** }\end{array}$ \\
\hline Migrant children & 5 & 85.5 & 51.9 & $5.17(4.16)$ & $7.93(8.36)$ \\
$\quad \begin{array}{l}\text { Non-local born } \\
\text { Local-born }\end{array}$ & 5 & 93.4 & 62.6 & $6.27(4.07)$ & $10.08(8.93)$ \\
$\begin{array}{l}\text { National population } * \\
\quad \text { Rural }\end{array}$ & 5 & 70.2 & 28.6 & $3.04(3.49)$ & $3.76(4.89)$ \\
$\quad$ Urban & 5 & 70.2 & & & \\
& 5 & 62.0 & NA & $3.92(4.27)$ & NA \\
\hline
\end{tabular}

* National statistics on caries prevalence were obtained through the latest (3rd) National Survey of Oral Health (PRC National Committee for Oral Health. Report of the third national survey of oral health. Ed. Xiaoquan Qi. People's Medical Publishing House. June 2008. ISBN 978-7-117-10149-3.)

** Rampant caries is defined as caries affecting the smooth surfaces of two or more maxillary incisors (Al-Malik MI, Holt RD, Bedi R. Erosion, caries and rampant caries in preschool children in Jeddah, Saudi Arabia. Community Dent Oral Epidemiol. 2002; 30(1):16-23.)

*** SD: standard deviation; dmft: decayed, missing, filled teeth; dmfs: decayed, missing, filled surfaces. 
Table 3. Parental knowledge/attitudes on oral health and children's oral health practice

\begin{tabular}{|c|c|c|}
\hline & $\mathbf{n}$ & $\%$ \\
\hline \multicolumn{3}{|l|}{ Children's Oral Health Practice } \\
\hline \multicolumn{3}{|l|}{ Bedtime feeding at 12 months of age } \\
\hline Nothing/water/pacifier & 108 & 83.7 \\
\hline Milk/formula/juice/nipple/sweets & 21 & 16.3 \\
\hline \multicolumn{3}{|l|}{ Sweet snacks or drinks between meals a day } \\
\hline 0-1 times & 81 & 61.8 \\
\hline 2-3 times & 37 & 28.2 \\
\hline$\geq 4$ times & 13 & 9.9 \\
\hline \multicolumn{3}{|l|}{ Sweet snacks before sleep without toothbrushing } \\
\hline Never/occasionally & 85 & 64.9 \\
\hline Frequently/almost every night & 46 & 35.1 \\
\hline \multicolumn{3}{|l|}{ Age when starting brushing teeth } \\
\hline$<3$ years & 23 & 17.6 \\
\hline 3 years & 22 & 16.8 \\
\hline $4-5$ years & 51 & 38.9 \\
\hline Not yet started & 35 & 26.7 \\
\hline \multicolumn{3}{|l|}{ Frequency of toothbrushing } \\
\hline No brushing & 35 & 26.7 \\
\hline Once a day & 81 & 61.8 \\
\hline Twice a day & 15 & 11.5 \\
\hline \multicolumn{3}{|l|}{ Child's dental visit } \\
\hline Ever & 14 & 10.8 \\
\hline Never & 116 & 89.2 \\
\hline \multicolumn{3}{|l|}{ Parental Knowledge/Attitudes on Oral Health } \\
\hline \multicolumn{3}{|l|}{ Main reason for caries } \\
\hline Sugar/sweets & 93 & 71.5 \\
\hline Insufficient toothbrushing & 70 & 53.8 \\
\hline Bacteria & 21 & 16.2 \\
\hline Tooth worm & 45 & 34.6 \\
\hline Excess heat & 15 & 11.5 \\
\hline \multicolumn{3}{|l|}{ Fatalistic oral health belief * } \\
\hline Agree & 13 & 10.0 \\
\hline Neutral & 14 & 10.8 \\
\hline Disagree & 103 & 79.2 \\
\hline \multicolumn{3}{|l|}{ Decayed baby teeth do not need to be treated } \\
\hline Agree & 40 & 30.8 \\
\hline Neutral & 23 & 17.7 \\
\hline Disagree & 67 & 51.6 \\
\hline \multicolumn{3}{|l|}{ Importance of teeth erupted after 6 years of age } \\
\hline Agree & 107 & 83.6 \\
\hline Neutral & 18 & 14.1 \\
\hline Disagree & 3 & 2.3 \\
\hline \multicolumn{3}{|l|}{ Detrimental effect of milk bottle on teeth } \\
\hline Agree & 79 & 60.8 \\
\hline Neutral & 21 & 16.2 \\
\hline Disagree & 30 & 23.1 \\
\hline \multicolumn{3}{|l|}{ Fluorides' effect on caries prevention } \\
\hline Agree & 64 & 49.6 \\
\hline Neutral & 45 & 34.9 \\
\hline Disagree & 20 & 15.5 \\
\hline \multicolumn{3}{|l|}{ Source of oral health knowledge } \\
\hline TV/radio & 80 & 62.0 \\
\hline Newspaper/magazine & 47 & 36.4 \\
\hline Family/relatives/friends & 8 & 6.2 \\
\hline Hospital pamphlet or medical/dental personnel & 9 & 7.0 \\
\hline Community program & 11 & 8.5 \\
\hline Schools & 11 & 8.5 \\
\hline Total & 138 & 100 \\
\hline
\end{tabular}

* Fatalistic oral health belief was gauged by the parental perception on the statement "having good or bad teeth is predetermined and has nothing to do with how one protects his/her teeth". 
Table 4. Oral health impacts on quality of life assessed by Early Childhood Oral Health Impact Scale (ECOHIS)

\begin{tabular}{|c|c|c|c|c|c|c|c|c|}
\hline \multirow[b]{2}{*}{ Impact } & & \multicolumn{3}{|c|}{ n (\%) } & \multicolumn{4}{|c|}{ Domain/Sub-domain Statistics } \\
\hline & & $\begin{array}{l}\text { Never or } \\
\text { hardly ever }\end{array}$ & $\begin{array}{c}\text { Occasionally, } \\
\text { often, or } \\
\text { very often } \\
\end{array}$ & $\begin{array}{l}\text { Don't } \\
\text { know }\end{array}$ & $\begin{array}{c}\text { One or more } \\
\text { impacts } \\
\text { n (\%) } \\
\end{array}$ & $\begin{array}{l}\text { Possible } \\
\text { range }\end{array}$ & $\begin{array}{l}\text { Mean } \\
\text { (SD) * }\end{array}$ & $\begin{array}{l}\text { Median } \\
(\mathrm{IQR}) * *\end{array}$ \\
\hline Child impact & & & & & 76 (58.9) & $0-36$ & $7.35(6.53)$ & $8.0(12.0)$ \\
\hline Child symptoms & How often has your child had pain in the teeth, mouth or jaws & $62(47.7)$ & $67(51.5)$ & $1(0.8)$ & $67(51.5)$ & $0-4$ & $1.37(1.16)$ & $2.0(2.0)$ \\
\hline \multirow[t]{5}{*}{ Child function } & $\begin{array}{l}\text { How often has your child ...... because of dental problems or } \\
\text { dental treatments? }\end{array}$ & & & & $60(46.2)$ & $0-16$ & 3.49 (3.27) & $4.0(6.0)$ \\
\hline & Had difficulty drinking hot or cold beverages & $92(70.8)$ & $36(27.7)$ & $2(1.5)$ & & & & \\
\hline & Had difficulty eating some foods & $79(60.8)$ & $49(37.7)$ & $2(1.5)$ & & & & \\
\hline & Had difficulty pronouncing any words & $91(70.0)$ & 37 (28.5) & $2(1.5)$ & & & & \\
\hline & Missed pre-school, daycare or school & $121(93.1)$ & $8(6.1)$ & $1(0.8)$ & & & & \\
\hline \multirow[t]{2}{*}{ Child psychology } & Had trouble sleeping & $92(71.3)$ & $35(27.1)$ & $2(1.6)$ & $42(32.6)$ & $0-8$ & $1.57(1.57)$ & $2.0(3.0)$ \\
\hline & Been irritable or frustrated & $103(79.8)$ & $24(18.6)$ & $2(1.6)$ & & & & \\
\hline \multirow[t]{2}{*}{ Self image and social interaction } & Avoided smiling or laughing & $115(89.1)$ & $12(9.3)$ & $2(1.6)$ & $15(11.6)$ & $0-8$ & $0.90(1.43)$ & $0(2.0)$ \\
\hline & Avoided talking & $116(89.9)$ & $11(8.5)$ & $2(1.6)$ & & & & \\
\hline Family impact & & & & & $55(42.6)$ & 0-16 & $2.93(2.83)$ & $3.0(5.0)$ \\
\hline \multirow[t]{3}{*}{ Parental distress } & $\begin{array}{l}\text { How often have you or another family member ... because of } \\
\text { your child's dental problems or dental treatments? }\end{array}$ & & & & $48(37.2)$ & $0-8$ & $1.91(2.00)$ & $2.0(3.0)$ \\
\hline & Been upset & $83(64.3)$ & $45(34.9)$ & $1(0.8)$ & & & & \\
\hline & Felt guilty & $97(75.2)$ & $31(24.0)$ & $1(0.8)$ & & & & \\
\hline \multirow[t]{2}{*}{ Family function } & Taken time off from work & $120(93.0)$ & $8(6.2)$ & $1(0.8)$ & $22(17.1)$ & $0-8$ & $1.02(1.22)$ & $0(2.0)$ \\
\hline & $\begin{array}{l}\text { How often has your child had dental problems or dental } \\
\text { treatments that had a financial impact on your family? }\end{array}$ & $110(85.3)$ & 18 (13.9) & $1(0.8)$ & & & & \\
\hline Total Score & & & & & 77 (60.2) & $0-52$ & $10.33(8.91)$ & $11.0(18.0)$ \\
\hline
\end{tabular}

* SD: standard deviation; ** IQR: inter-quartile range. 
Table 5. Linear regression analysis for caries severity (dmft score)

\begin{tabular}{|c|c|c|c|c|c|}
\hline \multicolumn{2}{|l|}{ Determinants of caries severity ( $\mathrm{dmft}$ score) } & \multicolumn{2}{|c|}{$\begin{array}{l}\text { Unstandardized } \\
\text { Coefficient }\end{array}$} & \multirow{3}{*}{$\begin{array}{c}\begin{array}{c}\text { Standardized } \\
\text { Coefficient }\end{array} \\
\text { B } * \\
-0.191\end{array}$} & \multirow{3}{*}{$\begin{array}{c}\text { Sig } \\
0.003\end{array}$} \\
\hline & & \multirow{2}{*}{$\frac{\mathbf{B} *}{-0.61}$} & \multirow{2}{*}{$\frac{\mathbf{9 5} \% \mathbf{C I} * *}{(-1.01,-0.22)}$} & & \\
\hline Parent's education & $\begin{array}{l}\text { (1) none; (2) primary; (3) lower secondary; (4) higher secondary; } \\
\text { (5) technical school; (6) junior college; (7) bachelor or above }\end{array}$ & & & & \\
\hline Place of birth & (1) local born; (2) non-local born & 2.61 & $(1.48,3.74)$ & 0.288 & $<0.001$ \\
\hline Bedtime feeding at 12-month-old & (1) nothing/water/pacifier; (2) breast/milk/formula/juice/sweet & 2.83 & $(1.39,4.26)$ & 0.248 & $<0.001$ \\
\hline Bedtime sweets & (1) never; (2) occasionally; (3) frequently; (4) almost every night & 0.89 & $(0.23,1.54)$ & 0.183 & 0.008 \\
\hline “Fluoride helps to prevent tooth decays" & $\begin{array}{l}\text { (1) totally agree; (2) agree; (3) neutral; } \\
\text { (4) disagree; (5) totally disagree }\end{array}$ & 1.29 & $(0.67,1.92)$ & 0.236 & $<0.001$ \\
\hline $\begin{array}{l}\text { "It's important to protect teeth that } \\
\text { erupt after } 6 \text { years of age" }\end{array}$ & $\begin{array}{l}\text { (1) totally agree; }(2) \text { agree; }(3) \text { neutral; } \\
\text { (4) disagree; }(5) \text { totally disagree }\end{array}$ & 1.09 & $(0.22,1.96)$ & 0.170 & 0.014 \\
\hline DI-S & Simplified debris index & 2.51 & $(1.33,3.69)$ & 0.285 & $<0.001$ \\
\hline $\mathrm{R}$ square $=0.575$ & Adjusted R square $=0.552$ & & & & \\
\hline
\end{tabular}

* Parameters were obtained through multiple linear regressions.

** CI: confidence interval.

Table 6. Linear regression analysis for oral health-related quality of life (ECOHIS score)

\begin{tabular}{|c|c|c|c|c|c|}
\hline \multirow{2}{*}{\multicolumn{2}{|c|}{ Determinants of oral health-related quality of life (ECOHIS score) }} & \multicolumn{2}{|c|}{$\begin{array}{c}\text { Unstandardized } \\
\text { Coefficient } \\
\end{array}$} & \multirow{2}{*}{$\begin{array}{c}\begin{array}{c}\text { Standardized } \\
\text { Coefficient }\end{array} \\
\text { B } * \\
\end{array}$} & \multirow[t]{2}{*}{ Sig } \\
\hline & & B * & $95 \% \mathrm{CI} * *$ & & \\
\hline Place of birth & (1) local born; (2) non-local born & 4.06 & $1.03-7.10$ & 0.212 & 0.009 \\
\hline dmft & Number of decayed missing, filled teeth & 0.95 & $0.61-1.29$ & 0.445 & $<0.001$ \\
\hline $\mathrm{R}$ square $=\mathbf{0 . 3 1 8}$ & Adjusted R square $=\mathbf{0 . 3 0 8}$ & & & & \\
\hline
\end{tabular}

* Parameters were obtained through multiple linear regressions.

** CI: confidence interval. 